\title{
Mestrado Profissional em Administração Universitária: desafios e perspectivas no processo da gestão universitária
}

\begin{abstract}
RESUMO
O presente artigo tem como objetivo compreender o desenvolvimento histórico e social de um Mestrado Profissional em Administração Universitária, com vistas ao processo de formação de gestores universitários. A pesquisa caracteriza-se por ser um estudo de caso, de natureza qualitativa, tendo como fonte de informações os docentes de um Mestrado Profissional em Administração Universitária, por meio de questionários. A pesquisa identificou existir um consenso entre os docentes entrevistados a respeito do papel e finalidade do Mestrado em Administração Universitária, como meio de formação e profissionalização da gestão universitária; da Universidade, como instituição social produtora, criadora e socializadora do conhecimento; e, da Gestão Universitária como ação administrativa em sentido amplo que deve considerar as finalidades específicas das universidades enquanto instituições sociais. Identificamos, nas percepções do corpo docente, o aspecto financeiro das políticas públicas como elemento que delimita e impede as ações de desenvolvimento da própria Universidade. Neste contexto, diante dos desafios e perspectivas vivenciadas pelo Mestrado em Administração Universitária, a contradição, que se evidencia, é que ao mesmo tempo que a formação é a essência do processo de gestão, esta formação é negada diante da concepção que se tem de gestão.
\end{abstract}

Palavras-chave: Mestrado Profissional. Gestão Universitária. Universidade Pública.

Carla Cristina Dutra Burigo Doutora em Educação Universidade Federal de Santa Catarina (UFSC) - Brasil carla.burigo@ufs.br

Alessandra de Linhares Jacobsen Doutora em Engenharia de Produção Universidade Federal de Santa Catarina (UFSC) - Brasil alessandradelinharesjacobsen@gmail.com

Ludmila Wiggers Mestre em Administração Universitária Universidade Federal de Santa Catarina (UFSC) - Brasil dpt/wiggers@hotmail.com 


\section{INTRODUÇÃO}

Este artigo apresenta sinteticamente os resultados de uma pesquisa (WIGGERS, 2015), que teve como fenômeno de investigação o Mestrado Profissional em Administração Universitária do Programa de PósGraduação em Administração Universitária (PPGAU) da Universidade Federal de Santa Catarina (UFSC).

O processo histórico do Mestrado Profissional em Administração Universitária está inicialmente ligado à preocupação com a formação dos servidores técnico- administrativos em educação da UFSC, no processo de atuação na área de gestão universitária. A trajetória de criação do Mestrado remonta a 2004, quando foi criada na UFSC a Pró-Reitoria de Desenvolvimento Humano e Social (PRDHS).

A PRDHS foi criada com o objetivo de auxiliar a Reitoria na área de Gestão de Pessoas, almejando melhorias no nível de qualidade de vida no trabalho dos servidores, a partir de sua potencialização como agente de transformação social e da humanização das relações de trabalho (BÚRIGO; SILVA, 2011).

A PRDHS instituiu, em 2006, uma Comissão com vistas a elaborar uma proposta de Curso de Pós-Graduação em nível de Mestrado na área de Gestão Universitária (BÚRIGO; SILVA, 2011, p. 3), com o objetivo de:

[...] formar servidores com uma visão crítica do processo de desenvolvimento da Universidade, almejando que pudessem romper alguns paradigmas cristalizados, de modo a propiciar alguns saltos qualitativos no fazer diário desta Instituição.

Neste contexto, após uma longa caminhada de tramitações acadêmicas e institucionais, surgiu o PPGAU, que em 2010 iniciou suas atividades junto ao Centro Sócio Econômico (CSE) da UFSC (BÚRIGO; SILVA, 2011), oferecendo o Mestrado Profissional em Administração Universitária, vinculado ao Departamento de Ciências da Administração (CAD).

É importante destacar que, embora tenha surgido a partir de uma demanda interna da UFSC (BÚRIGO; SILVA, 2011), o Mestrado Profissional em Administração Universitária é uma pós-graduação pública, não destinada exclusivamente aos servidores da UFSC, cujo objetivo é o de formar gestores para atuar em quaisquer Instituições de Ensino Superior (IES), públicas e privadas (UFSC, 2013a).

O presente artigo é parte de uma pesquisa maior (WIGGERS, 2015), que tem por objetivo compreender o desenvolvimento histórico e social do Mestrado Profissional em Administração Universitária da Universidade Federal de Santa Catarina, com vistas ao processo de formação de gestores junto à Instituição.

Os sujeitos trabalhados na pesquisa em comento (WIGGERS, 2015) foram docentes permanentes e colaboradores pertencentes ao quadro do PPGAU, no de 2014. A justificativa pela definição desta amostra sustenta-se pela vivência destes sujeitos no processo do desenvolvimento histórico e social do Mestrado Profissional em Administração Universitária. O caminho metodológico percorrido delineou-se em um estudo de caso, de natureza qualitativa, tendo como fonte de informações questionários.

O questionário foi estruturado a partir das seguintes categorias: Mestrado em Administração Universitária; Universidade; e, Gestão Universitária com vistas a atender ao objetivo inicialmente proposto (WIGGERS, 2015).

Para a organização do presente artigo partimos, do que dispomos de mais concreto: o Mestrado Profissional em Administração Universitária, sua concepção e processo de historicidade; após contextualizamos a nossa concepção de universidade; e depois de gestão como processo de profissionalidade. Na sequência apresentamos sinteticamente o olhar dos professores a partir das categorias investigadas. E ao final, com base no objetivo inicialmente proposto, retornamos ao ponto de partida buscando desvelar o que esta caminhada possa nos propiciar.

\section{MESTRADO PROFISSIONAL EM ADMINISTRAÇÃO UNIVERSITÁRIA DA UFSC}

Vinculado ao Programa de Pós-Graduação em Administração Universitária, o Mestrado Profissional em Administração Universitária surge em 2010, como uma demanda da própria Universidade. De acordo com Kobiyama, Silva e Perardt (2011), a ideia embrionária de criação de um curso de formação para gestores universitários surgiu, em meados de 1999, quando o Programa de Gestão Universitária (PROGEU) formava a 
primeira turma no curso de especialização em gestão universitária, na Instituição. Curso este, que despertou o interesse dos servidores técnico-administrativos em educação da UFSC, em prosseguir seus estudos em gestão universitária, em nível de mestrado.

Em 1999, foi constituída a primeira proposta para a criação de um curso de pós-graduação stricto-sensu em nível de Mestrado em Gestão Universitária, porém o projeto não se consolidou na época (KOBIYAMA; SILVA; PERARDT, 2011).

Posteriormente, em 2006, os servidores técnico-administrativos em educação da UFSC realizaram uma manifestação por meio de um abaixo-assinado e uma solicitação formal à Pró-Reitoria de Desenvolvimento Humano e Social para a criação do Curso, em comento. Constitui-se, então, uma comissão formada por servidores técnico-administrativos em educação e docentes, para elaborar a proposta do Curso (KOBIYAMA; SILVA; PERARDT, 2011).

A proposta foi acolhida pelo Centro Socioeconômico (CSE) e pelo Instituto de Pesquisas e Estudos em Administração Universitária (INPEAU) que, juntamente com a PRDHS, desenvolveram o projeto do mestrado profissional. O Projeto foi, então, aprovado nas instâncias acadêmicas da Instituição e encaminhado, em 2006, para a Coordenação de Aperfeiçoamento de Pessoal de Nível Superior (CAPES), tendo sido aprovado no final do ano de 2009 (KOBIYAMA; SILVA; PERARDT, 2011).

O Mestrado Profissional, de acordo com a CAPES (2013), é um Mestrado que enfatiza estudos e técnicas voltados ao desempenho de um alto nível de qualificação profissional, conferindo idêntico grau ao acadêmico. O Mestrado Profissional em Administração Universitária, contempla duas linhas de pesquisa (UFSC, 2013a, s/p):

a) Universidade e Sociedade; cujo principal objetivo é o de criar estudos que incrementem a interface entre a universidade e a sociedade organizada, especialmente organismos governamentais, fundações de amparo a pesquisa, Organizações Não-Governamentais (ONGS) e o segmento empresarial.

b) Gestão Acadêmica e Administrativa; visa estudar o processo de gestão de Instituições de Ensino Superior públicas e privadas, considerando questões no âmbito acadêmico e administrativo, com a finalidade de propor soluções aos desafios impostos pela flexibilização da gestão, em ambientes de mudanças contínuas; como ferramentas de gestão, sistemas gerenciais e avaliações institucionais.

O Mestrado Profissional em Administração Universitária tem por objetivo (UFSC, 2013b, Art. 1º.):

formar profissionais altamente qualificados, capazes de construir novos conhecimentos e práticas na área de ensino, pesquisa, extensão, desenvolvimento Institucional e administração universitária, em congruência com os valores da vida humana associada, e com os novos contextos sociais, políticos, econômicos e organizacionais.

Apesar do PPGAU ter nascido de uma demanda institucional na eminência de formar gestores para atuarem na UFSC, ele atende a qualquer cidadão que venha ao encontro do prescrito em seu Regimento (UFSC, 2013b).

O Mestrado historicamente vem se constituindo em um espaço onde o mestrando tem possibilidades concretas de repensar o seu fazer no contexto da gestão universitária. Este aluno tem um contexto diferenciador (SILVEIRA, 2013), que é ser potencialmente trabalhador de uma Instituição de Educação Superior, o que potencializa a essência do propósito de criação do Curso, ou seja, a formação na gestão universitária.

Acreditamos que a ação da gestão no contexto universitário perpassa também pela concepção que temos de universidade. Como concebemos a universidade no processo de desenvolvimento da sociedade é fundamental para as diretrizes de desenvolvimento do processo de gestão. Por outro lado, esta universidade que concebemos não é uma folha ao vento. Ela é sustentadora e ao mesmo tempo opositora da sociedade onde está inserida, pois é uma instituição atípica, podendo pensar além das raízes da razão, como uma instituição social (BÚRIGO, 2003). 


\section{A UNIVERSIDADE COMO INSTITUIÇÃO SOCIAL}

Concebemos a universidade como uma instituição, visando compreender o seu papel social, e sua inter-relação com a sociedade onde está inserida, tendo a formação como sua essência. Com base em Chauí (1999, p. 6), a universidade como instituição social:

[...] aspira à universalidade [...] a instituição tem a sociedade como seu princípio e sua referência normativa e valorativa, enquanto a organização tem apenas a si como referência, num processo de competição com outras que fixaram os mesmos objetivos particulares.

Segundo Chauí (1999), uma organização difere de uma instituição por ser definida por uma prática social determinada por suas ferramentas e funções, ou seja, está referida a um conjunto de meios administrativos particulares para a obtenção de um objetivo particular. Já, as instituições sociais dizem respeito às práticas sociais que perduram por meio do tempo pela adesão que encontram na maioria dos membros da sociedade, por possuírem objetivos entendidos enquanto comuns pela sociedade a qual pertencem. Neste sentido, os objetivos de uma universidade são compartilhados socialmente, dizem respeito à sociedade como um todo, não são particulares como os de uma organização.

Enquanto instituição social, a universidade ocupa um espaço público entre a sociedade civil e a autoridade do Estado. Ela é, ao mesmo tempo, contraditoriamente, legitimadora e opositora das ações ideológicas da sociedade e do Estado (BÚRIGO, 2003).

Chauí (2003) compreende que a universidade sempre foi uma instituição social, que exprime a estrutura e o modo de funcionamento da sociedade como um todo, fundada no reconhecimento público de sua legitimidade e de suas atribuições, com autonomia perante outras instituições sociais, estruturada por ordenamentos, regras, normas e valores de reconhecimento e legitimidade próprios.

A partir da defesa desta concepção de universidade como instituição social, Chauí (2003) ressalta que a reforma neoliberal do Estado, que, ao considerar a educação como um serviço que pode ser privado ou privatizado, situa a universidade como uma organização. Esta visão organizacional da universidade produz o que Chauí (1999) chama de universidade operacional: uma organização voltada para si mesma enquanto estrutura de gestão e de arbitragem de contratos. Definida e estruturada por normas e padrões alheios ao conhecimento e à formação intelectual, que se consubstancia, por exemplo, no aumento de horas-aula, na avaliação quantitativa de publicações, na multiplicação de participação em comissões e de elaboração de relatórios que balizam a produtividade docente.

Esta visão organizacional da universidade desestabiliza seus objetivos sociais, pois, de acordo com Chauí (2003), a educação deve ser compreendida e materializada como um investimento social e político, devendo constituir um direito e não um privilégio de poucos.

Pesquisas apontam (BÚRIGO, 2009) que a universidade, em especial a universidade pública, como instituição social, é um espaço privilegiado para o processo da formação, pois esta é a sua essência. Não podemos conceber uma universidade distante do processo da formação, como uma prática fundamentalmente educativa e social.

Todavia, a universidade, como instituição social, necessita ter condições favoráveis, reais e materiais, para poder realizar esta formação. Acreditamos que a formação de seus gestores é um potencial caminho para o desenvolvimento da sua essência, ou seja, a formação como uma prática educativa e social, inseparável da educação como resultado de pensar e refletir sobre a realidade.

\section{A GESTÃO UNIVERSITÁRIA COMO PROCESSO DE PROFISSIONALIDADE}

A gestão, de acordo com Bergue (2011), é uma ciência social aplicada que realiza formulações orientadas para a transformação da realidade. Ela formula princípios por meio de concepções, que permitem a descrição de situações cujo conteúdo corresponde a fatos ou situações empiricamente observáveis. De acordo com Schlickmann (2013, p. 44), as organizações são o principal objeto da administração, sendo as organizações definidas enquanto "[...] sistemas sociais cuja prioridade de atenção para a consecução de uma 
meta específica é considerada como característica que a distingue de outros sistemas".

Vale destacar, como também adverte Schlickmann (2013), que as organizações são também objeto de estudo de outros campos do conhecimento, como a sociologia, e que a ciência da administração utiliza muitas vezes os arcabouços teóricos de outras disciplinas, constituindo-se em uma ciência, de certa forma, interdisciplinar.

A ação da gestão parte do pressuposto de administrar com as pessoas, em uma ação compartilhada, coletiva (BÚRIGO; LOCH, 2006). Para tanto, se faz relevante compreender a diferença entre tecnologias e teorias de gestão.

Para Bergue (2011), as tecnologias de gestão são saberes sistematicamente referidos à ação, uma ciência aplicada, um conjunto de concepções e preceitos sobre como fazer, ou um know how. Como modelos, técnicas e métodos de atuação destinados à análise de problemas ou administração de rotinas. Já no contexto da teoria organizacional, a teoria da gestão, busca compreender como grupos e sujeitos se comportam em diferentes arranjos organizacionais institucionais.

Neste contexto, de acordo com Bergue (2011), qualquer concepção teórica está relacionada à prática, e vice-versa. Isto é, qualquer prática também contém concepções ou fragmentos teóricos. Mesmo que empiricamente, as práticas dos gestores contêm concepções teóricas, resultado das experiências vivenciadas pelos mesmos, e produzem generalidades em relação ao comportamento dos sujeitos, reações demonstradas por estes e em suas formas de agir.

Estas generalidades empíricas, que podem vir a interessar a determinados grupos, funcionam quase que da mesma forma, em certo sentido, como as teorias científicas, como lentes analíticas que permitem capturar e interpretar os fenômenos do mundo, do ambiente laboral.

A diferença entre as teorias empíricas e científicas, é que estas últimas são erigidas a partir do processo científico, ancoradas em referenciais e métodos que permitem a sustentação das afirmações produzidas segundo parâmetros e valores geralmente aceitos pela comunidade de pesquisadores, ou seja, coerentes com o paradigma científico vigente. Enquanto que os postulados empíricos são, muitas vezes, inconscientes e conflitantes, orientando a ação dos sujeitos sem um exame explícito de suas pressuposições teóricas, o que pode levar a algumas incoerências flagrantes no comportamento administrativo (BERGUE, 2011).

Assim sendo, eventos administrativos como planejamento, organização, processos e tecnologias empíricas de gestão são identificados por Oliveira (2012) muito antes do surgimento da Administração enquanto ciência. O surgimento da escrita cuneiforme na mesopotâmia pode ser considerado como a primeira tecnologia de gestão, tendo sido primeiramente utilizada para contabilidade, em especial para cobrança de impostos. Porém, a Administração Científica, e as teorias científicas de gestão, remontam ao final do Século XIX e início do Século XX.

Frederick W. Taylor é considerado o fundador da Administração Científica, fundamentada na aplicação de métodos da ciência positiva, racional e metódica aos problemas administrativos, objetivando alcançar a máxima produtividade. Para tanto, propôs métodos e sistemas de racionalização do trabalho e disciplina, por meio da fragmentação e hierarquização do trabalho. Também propôs incentivos salariais e prêmios, acreditando que as pessoas são motivadas exclusivamente por interesses salariais e materiais (MATOS; PIRES, 2006).

A teoria de Taylor, junto às de Fayol e Ford fazem parte do que Bergue (2011) chama de abordagem mecanicista da Administração. A teoria organizacional moderna, que pode ser datada a partir de 1958 (BERGUE, 2011), reconhece os equívocos dos modelos mecanicistas, propondo uma nova compreensão das organizações, dando maior centralidade ao Homem e compreendendo que este não pode ser reduzido a esquemas simples e mecanicistas, necessitando de reconhecimento de incentivos psicossociais, como sujeito do seu trabalho e não mero objeto de sua produção.

Esta reflexão teórica ao modelo mecanicista enfatiza a cooperação, valorização de grupos de trabalho, a diminuição de níveis hierárquicos, o autogerenciamento por setores e áreas, a delegação de tarefas, a responsabilidade e as decisões compartilhadas (MATOS; PIRES, 2006). Trata-se de um processo de flexibilização da lógica trabalhista, reconhecendo que a rigidez é um obstáculo à reestruturação e readequação de ações gerenciais (SPALTRO, 2004). 
Historicamente, diante dos modelos mecanicistas de gestão, pode-se constatar rupturas que só seriam possíveis a partir da absorção de concepções teóricas por parte dos gestores, de forma que estas subsidiem sua capacidade de refletir e ter competência, permitindo-lhes mais do que a reprodução acrítica de fórmulas e modelos gerenciais pré-definidos, possibilitando a prática de uma gestão consciente (BERGUE, 2011).

Um dos possíveis e concretos caminhos para a ruptura de modelos mecanicistas gerenciais se dá a partir do processo de formação, da profissionalidade, de concepções teóricas e práticas por parte dos gestores, diante da sua visão de homem, de mundo e de sociedade.

No geral, a concepção de gestão universitária perpassa também por esta premência de formação do seu gestor, e no singular esta formação necessita ser pensada e repensada no contexto particular onde esta universidade está inserida, principalmente diante das peculiaridades que permeiam a gestão universitária da esfera pública (BÚRIGO; LOCH, 2006).

De acordo com Kobiyama, Silva e Perardt (2011), e Silveira (2013), a gestão universitária difere daquela de uma empresa, ou organização qualquer, demandando habilidades e domínio de técnicas adequados à realidade universitária, de forma que as práticas da gestão empresarial, sendo ela pública ou privada, não podem ser exportadas diretamente para o setor público.

A gestão universitária é complexa e diferenciada, não havendo regra ou princípio que possa ser indiscriminadamente aplicado a todas as universidades ou IES. Pois, em especial as universidades, contêm especificidades de ensino, pesquisa e extensão, de orçamento e finanças, de gerenciamento de seus recursos e de desenvolvimento da sua área de gestão de pessoas.

Nas universidades brasileiras, o processo decisório é presidido pela figura do reitor, porém estruturalmente sua gestão é colegiada pelos seus pró-reitores e secretários, que se referenciam a um Conselho Superior que referenda os atos executivos da reitoria. Desta forma, o processo decisório nestas Instituições se dá mediante o mútuo ajuste entre atores pouco diferenciados, pois geralmente tanto o reitor, diretores de unidade e chefes de departamento são servidores da carreira técnico-administrativo em educação ou docente (LAUREANO, 2012).

Neste contexto, a gestão colegiada, coletiva, ou seja, compartilhada e encadeada entre os pares é essencial na concepção de que universidade desejamos construir (BÚRIGO; LOCH, 2006). Todavia, algumas ferramentas de gestão são fundamentais para este compartilhamento colegiado do ato da gestão, dentre eles, destacamos a formação.

Isto requer uma consciência coletiva, institucional de profissionalização da gestão. Pois entre a competência técnica e o compromisso político institucional, há um longo caminho a ser percorrido, que pode ser potencialmente amenizado pelo processo da formação.

Esta profissionalização da gestão se constitui a partir do momento em que a universidade pública mantém seus profissionais em processo de atualização e formação, que legitime a universidade perante a sociedade ao mesmo tempo em que assegura a produção de conhecimentos necessários para esta mesma sociedade (LAUREANO, 2012).

Nas Instituições Federais de Ensino Superior (IFES) brasileiras, esta formação é fundamentada pela Política Nacional de Desenvolvimento de Pessoal (PNDP) (BRASIL, 2006), que pauta pelo desenvolvimento permanente dos servidores, alinhado aos objetivos das instituições e pela busca da melhoria da eficiência, eficácia e do nível de qualidade dos serviços públicos prestados ao cidadão.

Esta política de formação delineada pelo Governo Federal (BRASIL, 2006) é uma política de gestão de pessoas orientada para o desenvolvimento do conjunto de conhecimentos, habilidades e atitudes necessárias ao desempenho do cargo e das funções dos servidores (LAUREANO, 2012).

A presente pesquisa, em seu objetivo, buscou ir além deste processo de formação. Ela buscou compreender o desenvolvimento histórico e social do Mestrado Profissional em Administração Universitária, com vistas ao processo de formação de seus gestores junto a UFSC, em nível de pós-graduação, que é uma possibilidade concreta de profissionalização da gestão.

Todavia, estamos cientes que esta é apenas uma possibilidade de formação. Porém, para a materialização da profissionalidade da gestão universitária há inúmeros caminhos que precisam ser percorridos, dentre eles as próprias condições concretas de trabalho. 
Contudo, sem dúvida, desde 2010 uma importante e fundamental ação está sendo concretizada por meio do Mestrado Profissional em Administração Universitária desvelando desafios e perspectivas no processo da gestão universitária na Instituição.

\section{O OLHAR DOS PROFESSORES}

Os professores investigados demonstram ter uma considerável vivência no mundo acadêmico, tendo possibilidades concretas de manifestar a percepção quanto a concepção do Mestrado Profissional em Administração Universitária, Universidade e Gestão Universitária.

Em sua grande maioria os professores estão desde a fundação do Mestrado, potencializando o conhecimento de criação do seu processo histórico e social. Cabe ressaltar que apesar da disponibilidade destes professores de responderem ao questionário mediante um efetivo compromisso com o desenvolvimento de uma pesquisa científica, eles representam apenas $23 \%$ do corpo docente do Mestrado em Administração Universitária.

De acordo com Triviños (1992) a amostra é considerada uma referência da população, delimitada pelo pesquisador a partir de critérios intencionais. Neste Estudo, a amostra se configurou a partir da disponibilidade dos professores ao responderem o questionário considerando, neste contexto, o tempo para a realização da coleta das informações. A interação no processo de análise das informações coletadas, sem dúvida, possibilitou construir um caminho, com vistas a atender os objetivos inicialmente propostos.

A respeito do processo de concepção do Mestrado Profissional, a grande maioria dos docentes participantes da pesquisa tiveram alguma participação neste contexto, e o ingresso no Programa representou a continuidade em suas pesquisas ou atividades letivas anteriores.

Isto nos possibilita considerar que a concepção do Programa perpassa pelo processo de formação e atuação dos seus docentes, no que tange à gestão universitária. Pois além do ministrar as aulas é um caminho concreto para o desenvolvimento de pesquisas. E isto ficou desvelado na fala dos docentes, ou seja, o Mestrado Profissional é um campo fértil para se pensar e repensar a prática da gestão a partir dela mesma.

Quanto à finalidade do Mestrado Profissional, na fala dos docentes, perpassa pelo formar e aperfeiçoar os quadros administrativos das IES, considerando seu papel relevante para a sociedade. Muito além de formar gestores é formar gestores universitários, concebendo neste contexto, a particularidade desta ação para o desenvolvimento da própria Instituição e da sociedade.

No que tange à Categoria Universidade, os docentes demonstraram consenso a respeito do papel da universidade enquanto produtora, criadora e socializadora do conhecimento, identificando-a com base em Chauí (1999) como uma instituição social, no processo de interação com a sociedade.

A respeito do impacto das políticas públicas, destacaram o financiamento como elemento central, no processo de desenvolvimento do que concebem como universidade. Este financiamento, como reflexo das políticas públicas, é um limitador no processo de identidade da universidade como instituição social. Sendo essencialmente desafiante o que é necessário fazer o que verdadeiramente se faz no desenvolvimento do que se define como trabalho acadêmico, ou seja, o ensino, a pesquisa e a extensão, diante das ações de financiamento das políticas públicas.

As políticas públicas vão muito além da questão do financiamento, porém no olhar dos entrevistados este é um elemento que interfere essencialmente na gestão universitária, como uma ação que emana as condições de realização das atividades de ensino, pesquisa e extensão.

$\mathrm{Na}$ visão dos docentes participantes da pesquisa, a gestão universitária é uma forma específica de gestão, que deve levar em conta as características específicas das IES. Neste contexto, ao falar do PPGAU é dada ênfase à importância da formação, e consequentemente à profissionalização, no processo da gestão universitária.

Os resultados da pesquisa apontam que, embora seja incontestável o papel do PPGAU para uma transformação positiva das IES, os quadros formados pelo Curso, capacitados para pensar os tão necessários caminhos de gestão, não necessariamente ocupam as posições necessárias para realizarem esta mudança. 
Isto ocorre porque os acessos aos principais cargos de staff superior e intermediário se dão por ações políticas internas à Instituição e afinidades com a gestão no comando, e isso delimita tanto a ação da gestão quanto os próprios quadros formados, que se veem impossibilitados de ocupar as posições para as quais se formaram.

Neste contexto, podemos pontuar que, ao mesmo tempo em que os gestores concebem a relevância da profissionalização da gestão no contexto da formação da gestão universitária, esta atuação necessita ser repensada pelos próprios gestores do que compreendem por profissionalização. Pois entre a competência técnica e o compromisso político, há um caminho que necessita ser percorrido por meio da formação, da profissionalização da gestão universitária, como defendem os professores na pesquisa realizada (WIGGERS, 2015).

\section{CONSIDERAÇÕES FINAIS}

Ao resgatar o objetivo inicialmente proposto do presente artigo em compreender o desenvolvimento histórico e social do Mestrado Profissional em Administração Universitária, com vistas ao processo de formação de gestores universitários, podemos pontuar que o Programa de Pós-Graduação em Administração Universitária se constituiu e se constitui para a profissionalização da gestão universitária. Historicamente, foi constituído por uma demanda dos servidores técnico-administrativos em educação da UFSC, mas socialmente ele vai além desta demanda, potencializando gestores universitários de várias IES de todo o Brasil.

A Pesquisa realizada (WIGGERS, 2015), demonstrou que o levantamento do processo de desenvolvimento histórico e social do Mestrado Profissional em Administração Universitária da UFSC revelou ter sido este um processo longo, fruto de demandas antigas da própria comunidade universitária, cujo embrião se encontra em aspirações existentes desde a fundação da Instituição.

O PPGAU também é, de certa forma, fruto de processos anteriores à sua própria fundação, na busca da profissionalização da gestão universitária, por uma educação superior pública e de bom nível de qualidade. Durante o processo histórico de concepção e constituição do PPGAU é possível identificar as mudanças nas concepções da gestão universitária, que passam a considerar cada vez mais a importância da formação e da sua profissionalização.

A partir deste ponto de vista, acreditamos que o PPGAU foi uma conquista importante, mas não é um fim em si, mas um meio de formação e profissionalização da gestão universitária, que perpassa pela concepção que se tem de universidade.

No que tange à concepção e papel social da universidade, os docentes demonstraram consenso a respeito do papel da universidade enquanto produtora, criadora e socializadora do conhecimento, além de reconhecerem a importância social da mesma para o desenvolvimento da sociedade. Esta relação da universidade com a sociedade é contraditória. Pois, ao mesmo tempo a universidade é legitimadora e opositora da sociedade onde está inserida. Porém, ambas se sustentam no processo das interações que estabelecem.

Já sobre o impacto das políticas públicas, foi destacado essencialmente o aspecto financeiro, como elemento que delimita e impede as ações de desenvolvimento da própria universidade.

A respeito das percepções do corpo docente do Mestrado Profissional em Administração Universitária sobre a concepção de gestão, foi possível observar que a maior parte dos docentes, participantes da pesquisa, situam a gestão universitária como uma ação administrativa em um sentido amplo, mas que deve considerar as peculiaridades das finalidades específicas das universidades, tendo em vista que estas são instituições sociais, que devem produzir e disseminar conhecimento tendo comprometimento com valores éticos, culturais, ideológicos, de dignidade, equidade e justiça social.

Finalmente, a respeito da constituição da gestão universitária na UFSC, e do impacto do PPGAU na mesma, as informações coletadas tocaram diretamente no que seja talvez o principal desafio imposto ao PPGAU e aos quadros por ele formados, ou seja, o de garantir que estes quadros qualificados tenham acesso às posições gerenciais para as quais foram preparados, já que o acesso aos principais cargos de staff superior 
e intermediário se dão por ações políticas e afinidades com a gestão no comando.

Esta questão é crucial, e um desafio que vai além das ações do PPGAU, e que perpassa também pelo reconhecimento da UFSC sobre a constituição e finalidade deste Programa. Pois acreditamos que entre a competência técnica e o compromisso político do gestor, um caminho necessita ser trilhado, que é o da formação.

Neste contexto, diante dos desafios e perspectivas vivenciadas pelo Mestrado em Administração Universitária, a contradição que se evidencia como resultado da pesquisa em comento (WIGGERS, 2015) é que ao mesmo tempo que a formação é a essência do processo de gestão, esta formação é negada diante da concepção que se tem de gestão.

Quiçá que uma das possíveis ações para se vencer esta contradição seja a de socializar os trabalhos de pesquisas até então desenvolvidos pelo PPGAU, com vistas a disseminar o potencial acadêmico produzido, que envolve essencialmente ações da gestão universitária. Outra possibilidade seria a de criação de um Lattes para o Curso, com vistas a divulgar as dissertações produzidas no âmbito da gestão universitária.

Sem dúvida o PPGAU, por meio do Mestrado em Administração Universitária, é uma realidade potencializadora do que se entende por universidade, essencialmente do que se percebe diante da formação da gestão universitária. A essência deste Programa é a formação de gestores, na concepção da profissionalização. Para tanto, alguns desafios precisam ser vencidos, no contexto do que se concebe por gestão, na perspectiva de chegarmos à sua profissionalização, na perspectiva de potencializarmos a universidade a partir da qual compreendemos.

\title{
PROFESSIONAL MASTER'S DEGREE IN UNIVERSITY ADMINISTRATION: CHALLENGES AND PERSPECTIVES IN THE PROCESS OF UNIVERSTY MANAGEMENT
}

\begin{abstract}
This article seeks to understand the historical and social development of the Professional Master's Degree in University Administration aiming at the training process of the managers. This study is characterized by a case study with qualitative nature, having as information source professors of the Professional Master's Degree in University Administration, through questionnaires. The research identified that there is consensus among professors interviewed about the role and purpose of the Master's Degree in University Administration as: training and professionalization of university management; of the university as a social institution, producer, creator and form of socializing of knowledge; and of University Management, in a broad sense, as administrative action that should consider the specific aims of universities as social institutions. The research showed the professors' perceptions of the financial aspect of public policies as an element that imposes limitations and prevents the development actions of the university itself. In this context, given the challenges and perspectives experienced by the Master's Degree in University Administration, the evident contradiction is that, while training is the essence of the management process, this training is denied by the concept existing of management.
\end{abstract}

Keywords: Professional Master's Degree. University Management. Public University.

\section{REFERÊNCIAS}

BERGUE, Sandro Trescastro. Modelos de Gestão em Organizações Públicas. Caxias do Sul: EDUCS, 2011.

BRASIL. Decreto no 5.707, de 23 de fevereiro de 2006. Institui a Política e as Diretrizes para o

Desenvolvimento de Pessoal da administração pública federal direta, autárquica e fundacional, e regula dispositivos da lei no 8.112, de 11 de dezembro de 1990. 2006. Disponível em: <http://www.planalto.gov. br/ccivil_03/_Ato2004-2006/2006/Decreto/D5707.htm>.Acesso em: 15 fev. 2015. 
BÚRIGO, Carla Cristina Dutra. O trabalho acadêmico do professor universitário no processo de desenvolvimento do espaço público na universidade federal: um estudo de caso na Universidade Federal de Santa Catarina e na Universidade Federal do Rio Grande do Sul. 2003. Tese (Doutorado) Universidade Federal do Rio Grande do Sul, Porto Alegre.

BÚRIGO, Carla Cristina Dutra. A Formação de professores da educação básica nos sistemas educacionais da Argentina, do Brasil e do Uruguai. Porto Alegre, 2009. Relatório (Pós-doutorado) - Universidade Federal do Rio Grande do Sul, Porto Alegre.

BÚRIGO, Carla Cristina Dutra; LOCH, Clésar Luiz. Universidade Pública Federal Brasileira: Democraticamente Massificada. In: Colóquio Internacional sobre a Gestão Universitária na América do Sul, 6., 2006, Blumenau. Anais... Blumenau: FURB, 2006.

BÚRIGO, Carla Cristina Dutra; SILVA, Luiz Henrique Vieira. A sala de aula como ambiente de incubação de ideias: ensaios na perspectiva do desenvolvimento humano e social. 2011. Disponível em: <http://www. semformprof.fhuce.edu.uy/materiales/ARTICULO14.pdf>. Acesso em: 10 nov. 2015.

CAPES. Tabela de Áreas de Conhecimento/Avaliação. 2013. Disponível em: <http://www.capes.gov.br/ avaliacao/instrumentos-de-apoio/tabela-de-areas-do-conhecimento-avaliacao >. Acesso em: 15 maio 2014.

CHAUÍ, Marilena. A Universidade Operacional. Avaliação, Campinas, v. 4, n. 3, p. 3-8, set. 1999.

CHAUÍ, Marilena. A universidade sob nova perspectiva. Revista Brasileira de Educação, Rio de Janeiro, n. 24, p. 5-15, set./dez. 2003.

KOBIYAMA, Adriana R. C. E.; SILVA, Elizabeth C. Rosa e; PERARDT, Susany. O Mestrado Profissional em Administração Universitária da Universidade Federal de Santa Catarina: um estudo de caso sobre o processo de criação e implantação. 2011. Disponível em: <https://repositorio.ufsc.br/xmlui/bitstream/hand le/123456789/32856/8.5.pdf?sequence=1>. Acesso em: 10 nov. 2015.

LAUREANO, Rogério João. Desafios da Gestão por Competência por meio das Ações de Capacitação na Universidade Federal de Santa Catarina. 2012. Dissertação (Mestrado) - Universidade Federal de Santa Catarina, Florianópolis.

MATOS, Eliane; PIRES, Denise. Teorias administrativas e organização do trabalho: de Taylor aos dias atuais, influências no setor saúde e na enfermagem. [2006]. Disponível em: <http://www.scielo.br/scielo. php?script=sci_arttext\&pid=S0104-07072006000300017\&lng=en\&nrm=iso >. Acesso em: 15 ago. 2013.

OLIVEIRA, Djalma Pinho Rebouças. História da Administração: como entender as origens, as aplicações e as evoluções da administração. São Paulo: Atlas, 2012.

SCHLICKMANN, Raphael. Administração Universitária: desvendando o campo científico no Brasil. 2013. Tese (Doutorado) - Universidade Federal de Santa Catarina, Florianópolis.

SILVEIRA, Evandro. Resultados da formação dos egressos do Programa de Pós-Graduação em Administração Universitária na Gestão da Universidade Federal de Santa Catarina. 2013. Trabalho de Conclusão de Curso (Graduação) - Universidade Federal de Santa Catarina, Florianópolis.

SPALTRO, Enzo. A boa educação. In: LANER, Aline dos; CRUZ JÚNIOR, João Benjamin. Repensando as 
organizações: da formação à participação. Florianópolis: Fundação Boiteux, 2004. p. 127-135.

TRIVIÑOS, Augusto Nibaldo Silva. Introdução à pesquisa em ciências sociais: a pesquisa qualitativa em educação. São Paulo: Atlas, 1992.

UNIVERSIDADE FEDERAL DE SANTA CATARINA (UFSC). Mestrado em Administração Universitária. Apresentação. 2013a. Disponível em: <http://ppgau.ufsc.br/apresentação>. Acesso em: 15 ago. 2013.

UNIVERSIDADE FEDERAL DE SANTA CATARINA (UFSC). Mestrado em Administração Universitária. Legislação. Regimento do PPGAU. 2013b. Disponível em: <http://ppgau.ufsc.br/files/2012/05/REGIMENTO08.06.11-p-pagina.pdf>. Acesso em: 15 ago. 2013.

WIGGERS, Ludmila. O Mestrado Profissional em Administração Universitária: desafios e perspectivas no processo da gestão universitária, a partir do olhar dos seus docentes. 2015. Dissertação (Mestrado) Universidade Federal de Santa Catarina, Florianópolis. 